\title{
Article \\ Simultaneous Determination of 23 Mycotoxins in Broiler Tissues by Solid Phase Extraction UHPLC-Q/Orbitrap High Resolution Mass Spectrometry
}

\author{
Youyou Yang ${ }^{1, *,+} \mathbb{D}$, Zhuolin $\mathrm{He}^{2,+}$, Lei Mu ${ }^{3,4}$, Yunfeng Xie ${ }^{3,4, *}$ and Liang Wang ${ }^{2}$ \\ 1 Institute of Animal Sciences of Chinese Academy of Agricultural Sciences, Beijing 100193, China \\ 2 College of Life Science and Technology, Xinjiang University, Urmuqi 830046, China; \\ hz1863454690@163.com (Z.H.); WL1390593786@163.com (L.W.) \\ 3 China Oil \& Foodstuffs Corporation (COFCO) Nutrition and Health Research Institute, Beijing 102209, China; \\ mulei1@cofco.com \\ 4 Beijing Key Laboratory of Nutrition Health and Food Safety, Beijing 102209, China \\ * Correspondence: yangyou229@126.com (Y.Y.); xieyunfeng@cofco.com (Y.X.) \\ + These authors contributed equally to this work.
}

Citation: Yang, Y.; He, Z.; Mu, L.; Xie, Y.; Wang, L. Simultaneous Determination of 23 Mycotoxins in Broiler Tissues by Solid Phase Extraction UHPLC-Q/Orbitrap High Resolution Mass Spectrometry. Separations 2021, 8, 236. https:// doi.org/10.3390/separations8120236

Academic Editor: Erica Liberto

Received: 22 October 2021

Accepted: 22 November 2021

Published: 4 December 2021

Publisher's Note: MDPI stays neutral with regard to jurisdictional claims in published maps and institutional affiliations.

Copyright: (c) 2021 by the authors. Licensee MDPI, Basel, Switzerland. This article is an open access article distributed under the terms and conditions of the Creative Commons Attribution (CC BY) license (https:// creativecommons.org/licenses/by/ $4.0 /)$.

\begin{abstract}
Mycotoxins are a type of toxins harmful for not only animal but also human health. Cooccurrence of multi-mycotoxins could occur for food infected by several molds, producing multimycotoxins. It is necessary to develop corresponding determination methods, among which current mass spectrometry (MS) dominates. Currently, the accurate identification and quantitation of mycotoxins in complex matrices by MS with low resolution is still a challenge since false-positive results are typically obtained. Here, a method for the simultaneous determination of 23 mycotoxins in broiler tissues using ultra-high performance liquid chromatography-quadrupole/orbitrap HRMS was established. After the extraction by acetonitrile-water-formic acid (80:18:2, $v / v / v)$, the purification by multifunctional purification solid phase extraction cartridges and the chromatographic separation on a C18 column, representative mycotoxins were determined by HRMS in full scan/data-dependent MS/MS acquisition mode. The quantitation was based on the external standard method. An MS/MS database of 23 mycotoxins was established to achieve qualitative screening and simultaneous quantification. Mycotoxins had a good linear relationship within a certain concentration range with correlation coefficients $\left(\mathrm{r}^{2}\right)$ larger than 0.991 as well as the limit of quantitation of $1.80-300 \mu \mathrm{g} / \mathrm{kg}$. The average recoveries at three different levels of low, medium and high fortification were $61-111 \%$ with relative standard deviations less than $13.5 \%$. The method was fast, accurate, and suitable for the precise qualification of multiple mycotoxins in broiler tissues. $15 \mu \mathrm{g} / \mathrm{kg}$ zearalenone (ZEN) was detected in one liver sample among 30 samples from markets including chicken breast meat, liver, and gizzards. The result illustrated that the pollution of ZEN should not be neglected considering its harmful effect on the target organ of liver.
\end{abstract}

Keywords: broiler tissue; orbitrap high resolution mass spectrometry; mycotoxins; rapid screening; solid phase extraction

\section{Introduction}

Mycotoxins are secondary metabolites with low molecular weight, approximately of $<1000 \mathrm{Da}$, produced by fungus species during growth and proliferation. The corresponding classification is difficult due to the complex structures and origins. Mycotoxins include group 1 and group 2B carcinogens (for example, aflatoxins (AFs)) are considered as the most toxic. In addition, there also exist modified and emerging mycotoxins. Mycotoxins which are harmful for animal liver and decrease animal' immunity and reproduction capacity can enter animal derived foods including meat, egg and milk and lead to residue through food chain, storage and processing, severely threatening human and animal 
health [1,2]. Currently, there are more than 400 mycotoxins, only a few of which are daily regulated and routinely monitored [3]. The current research about the residue determination of mycotoxins paid more attention to feed, grain, and oil to prevent them from entering the food chain. However, the detection of mycotoxins in meat (especially animal derived organs) was seldom reported. It was determined that the elimination time of mycotoxin residue in liver and muscle reached the quantitative value within at least 11-18 d [4]. Zearalenone (ZEN) in chicken serum was completely eliminated after $7 \mathrm{~d}$ with oral administration of the feed polluted by mycotoxins. However, there existed ZEN in both liver and faeces [5,6]. Mycotoxin residue in liver, kidney, muscle and milk of animal derived from food was mainly due to oral intake of the feed polluted by mycotoxins. Through food chain, mycotoxins entered the human body, threatening the human health [7-9]. Mycotoxin pollution which was widespread and uncontrollable has become a crucial aspect of animal derived food safety.

Over the last two decades, considering the determination of mycotoxins, MS including tandem MS and HRMS dominated (as high as 55\%). The determination methods of mycotoxins mainly included HPLC [10,11], GC [12,13], and LC-MS/MS [14-19]. Tandem MS for mycotoxins has been widely studied, focusing on multi-mycotoxin residue analysis and quantitation which was "golden standard". Tandem MS such as triple quadrupole (QQQ) of unit resolution MS selected multiple reaction monitoring (MRM) for the quantitation. The ion transitions and related parameters were necessary to be optimized sequentially, which were labor and time consuming when aiming at a large number of targets. The unit resolution MS was susceptible to the isobaric ion, allowing potential false positive phenomenon [19].

Recently, HRMS including Q/orbitrap and time of flight has been utilized in the determination of mycotoxins, which mainly focused on method development for avoiding matrix interference and accurate identification. Previous research work was more focused on the determination of single or a type of mycotoxins with a relative narrow covering range. Q/orbitrap HRMS has lots of advantages such as high resolution and high accuracy, which can realize accurate screening. It can obtain accurate molecular weights of compounds as well as the fragment ions under high resolution and with relatively strong anti-interference capacity $[20,21]$. Its most attractive advantage is the feasibility with target, non-target, and retrospective analysis. The current reported research about the determination of mycotoxins in meat has been mainly based on the unit resolution MS. The combination of UHPLC-Q/orbitrap HRMS has been utilized in the determination of pollutants in animal derived food [21] and pesticide residue [22].

In addition, the pretreatment method of mycotoxins has been mainly coupled with tandem MS. The corresponding coupling with HRMS was seldom. Currently, only QuEChERS method has been coupled to HRMS. However, fumonisins (FBs) which were known to be difficult to analyze with QuEChERS, were not considered by HRMS [23].

Considering the dietary habit of eating chicken meat as well as liver and gizzard in China, it was crucial to develop methods for analyzing mycotoxins in different broiler tissues and organs. In this work, A total of 23 mycotoxins including $\mathrm{AFs} \mathrm{AFTB}_{1}, \mathrm{AFTB}_{2}$, $\mathrm{AFTG}_{1}, \mathrm{AFTG}_{2}, \mathrm{AFTM}_{1}, \mathrm{AFTM}_{2}$ ), deoxynivalenol (DON), 3-acetyldeoxynivalenol (3ADON), 15-acetyldeoxynivalenol (15-ADON), de-epoxydeoxynivalenol (DOM), T-2 toxin (T-2), HT-2 toxin (HT-2), FBs $\left(\mathrm{FB}_{1}, \mathrm{FB}_{2}, \mathrm{FB}_{3}\right)$, ochratoxin A (OTA), ochratoxin (OTB), zearalanone (ZAN), zearalenone (ZEN), $\alpha$-zearalanol $(\alpha$-ZAL), $\beta$-zearalanol ( $\beta$-ZAL), $\alpha$ zearalenol $(\alpha$-ZOL) and $\beta$-zearaalenol ( $\beta$-ZOL) in broiler tissues were determined by solid phase extraction (SPE)-UHPLC-Q/orbitrap HRMS for rapid and accurate identification and quantitation, providing supports for animal derived food safety.

\section{Materials and Methods}

\subsection{Reagents}

$\operatorname{AFTB}_{1}(2 \mu \mathrm{g} / \mathrm{mL}), \operatorname{AFTB}_{2}(0.5 \mu \mathrm{g} / \mathrm{mL}), \operatorname{AFTG}_{1}(2 \mu \mathrm{g} / \mathrm{mL}), \operatorname{AFTG}_{2}(0.5 \mu \mathrm{g} / \mathrm{mL})$, $\operatorname{AFTM}_{1}(0.5 \mu \mathrm{g} / \mathrm{mL}), \operatorname{AFTM}_{2}(0.5 \mu \mathrm{g} / \mathrm{mL}), \mathrm{FB}_{1}(50 \mu \mathrm{g} / \mathrm{mL}), \mathrm{FB}_{2}(50 \mu \mathrm{g} / \mathrm{mL}), \mathrm{FB}_{3}(50 \mu \mathrm{g} / \mathrm{mL})$, 
DON $(100 \mu \mathrm{g} / \mathrm{mL}), \operatorname{DOM}(25 \mu \mathrm{g} / \mathrm{mL}), 3-A D O N(100 \mu \mathrm{g} / \mathrm{mL}), 15-A D O N(100 \mu \mathrm{g} / \mathrm{mL})$, T-2 toxin $(100 \mu \mathrm{g} / \mathrm{mL})$, HT-2 toxin $(100 \mu \mathrm{g} / \mathrm{mL})$, STC $(50 \mu \mathrm{g} / \mathrm{mL})$, OTA $(10 \mu \mathrm{g} / \mathrm{mL})$, OTB $(10 \mu \mathrm{g} / \mathrm{mL})$ were purchased from Romer Labs Co., Ltd. (Tulln, Austria). ZAN $(100 \mu \mathrm{g} / \mathrm{mL})$, ZEN $(100 \mu \mathrm{g} / \mathrm{mL}), \alpha$-ZAL $(100 \mu \mathrm{g} / \mathrm{mL}), \alpha$-ZEL $(100 \mu \mathrm{g} / \mathrm{mL}), \beta-Z O L(100 \mu \mathrm{g} / \mathrm{mL})$, and $\beta$-ZOL $(100 \mu \mathrm{g} / \mathrm{mL})$ were purchased from Anpel Co., Ltd. (Shanghai, China). Chicken breast, liver and kidneys were purchased from local super market.

Methanol and acetonitrile were all HPLC grade and purchased from Fisher Scientific (Pittsburgh, PA, USA). Water was purified by a Milli Q Advantaged A10 water purification system (Millipore, Bedford, MA, USA). Formic acid for UPLC/LC-MS were from Anpel Co., Ltd. (Shanghai, China). SPE columns with Captiva-EMR Lipid (600 mg, $6 \mathrm{~mL}$,) and Oasis PRIME HLB (600 mg, 6 mL) were from Agilent Technologies (Santa Clara, CA, USA) and Waters (Shanghai, China).

\subsection{Instrument Conditions}

Separation and detection of mycotoxins performed in the Q-Exactive system combined with Ultimate 3000 LC (Thermofisher, San Jose, CA, USA). Separation was fulfilled using a CORTECS C18 column $(2.1 \times 100 \mathrm{~mm}, 1.6 \mu \mathrm{m}$; Waters, Wexford, Ireland). The injection volume was set at $10 \mu \mathrm{L}$ and the flow rate was maintained at $0.2 \mathrm{~mL} / \mathrm{min}$. The mobile phase was composed of water ( $0.1 \%$ formic acid) as eluent $\mathrm{A}$ and methanol as eluent $\mathrm{B}$. The gradient elution program was shown in Table 1 . The mass spectrometer was equipped with a heated electrospray ionization (H-ESI) source. Data with positive and negative modes were acquired through data-dependent acquisition, respectively. The mass spectrometer parameters were as follows: spray voltage, $3000 \mathrm{~V}( \pm)$; auxiliary gas heater temperature, $350{ }^{\circ} \mathrm{C}$; capillary temperature, $320^{\circ} \mathrm{C}$; sheath gas flow rate $40 \mathrm{Arb}$; auxiliary gas flow rate, 15 Arb; scan range, 50-600 m/ $z$; collision energy (NCE): 20, 30, $40 \mathrm{~V}$; the resolving power for MS1 and MS2, 70,000 and 17,500, respectively.

Table 1. Gradient elution programs.

\begin{tabular}{|c|c|c|c|c|c|c|c|}
\hline \multirow{2}{*}{$\begin{array}{l}\text { Acquisition } \\
\text { Mode }\end{array}$} & \multirow{2}{*}{$\begin{array}{l}\text { Time } \\
(\mathrm{min})\end{array}$} & \multicolumn{2}{|c|}{ Gradient (\%) } & \multirow{2}{*}{$\begin{array}{l}\text { Acquisition } \\
\text { Mode }\end{array}$} & \multirow{2}{*}{$\begin{array}{l}\text { Time } \\
(\mathrm{min})\end{array}$} & \multicolumn{2}{|c|}{ Gradient (\%) } \\
\hline & & A & B & & & $\mathbf{A}$ & B \\
\hline \multirow{7}{*}{$\begin{array}{l}\text { Positive } \\
\text { mode }\end{array}$} & 1 & 70 & 30 & \multirow{7}{*}{$\begin{array}{l}\text { Negative } \\
\text { mode }\end{array}$} & 1 & 97 & 3 \\
\hline & 6.5 & 45 & 55 & & 2 & 45 & 55 \\
\hline & 8.5 & 45 & 55 & & 9 & 30 & 70 \\
\hline & 10 & 20 & 80 & & 10 & 1 & 99 \\
\hline & 12 & 20 & 80 & & 11 & 1 & 99 \\
\hline & 12.1 & 70 & 30 & & 11.1 & 97 & 3 \\
\hline & 16.1 & 70 & 30 & & 15 & 97 & 3 \\
\hline
\end{tabular}

\subsection{Sample Preparation}

Weigh $2.00 \pm 0.05 \mathrm{~g}$ of the minced sample into a $50 \mathrm{~mL}$ centrifuge tube. $10 \mathrm{~mL}$ acetonitrile/water/formic acid $(80 / 18 / 2, v / v / v)$ were added. The mixture was vortexed for $1 \mathrm{~min}$ and processed the ultrasonication at $30{ }^{\circ} \mathrm{C}$ for $20 \mathrm{~min}$, followed by centrifugation at $8000 \mathrm{rpm}$ for $10 \mathrm{~min} .5 \mathrm{~mL}$ of the supernatant was transferred to the Captiva-EMR Lipid and controlled at the eluting rate of 3 drops/s. Right after the solution flowed through the column, $1 \mathrm{~mL}$ acetonitrile/water $(80 / 20, v / v)$ was added. Both of the elution solutions were collected and nearly dried through the nitrogen flow at $40{ }^{\circ} \mathrm{C}$. The dried eluents were redissolved in a mixture of methanol/water/formic acid $(250 \mu \mathrm{L}, 30 / 70 / 0.1, v / v / v)$, vortexed for $1 \mathrm{~min}$, ultrasonicated for $5 \mathrm{~min}$, and centrifuged at 12,000 rpm for $10 \mathrm{~min}$. The supernatant was transferred into a vial for analysis.

\subsection{Method Validation}

Linearity, sensitivity, accuracy, and precision were investigated according to Criterion on quality control of laboratories-chemical testing of food (GB 27404). Calibration curves were constructed through the responses versus the concentrations spiked in the blank ma- 
trix. The limit of detection ( $\mathrm{LOD}, \mathrm{S} / \mathrm{N}=3$ ) and the limit of quantification $(\mathrm{LOQ}, \mathrm{S} / \mathrm{N}=10)$ were calculated in light of the blank matrix with the lowest spiking level. Recoveries and stability were investigated using blank samples fortified with three different levels. Samples of each level were prepared in six replicates. The recovery of each mycotoxin was calculated as the ratio of the mean peak areas between the samples spiked before extraction and the samples spiked after extraction. The relative standard deviation (RSD) of peak areas in six replicates for each mycotoxin at three spiking levels represented the stability of the method.

\section{Results and Discussion}

\subsection{The Optimization of LC-HRMS Conditions}

In the optimization procedure of the chromatography conditions, the column type and the mobile phase were investigated. Compared with Thermo Scientific Accucore C18 column $(2.1 \mathrm{~mm} \times 100 \mathrm{~mm}, 2.6 \mu \mathrm{m})$, the separation efficiency of CORTECS-UPLC-C18 $(2.1 \mathrm{~mm} \times 100 \mathrm{~mm}, 1.6 \mu \mathrm{m})$ was higher, which could guarantee the good peak shape of each target compound. Besides, the analysis time was shorter and the resolution was relatively higher. Thus, analysis of 23 mycotoxins could be fulfilled within a shorter time. In this experiment, methanol was selected as the organic phase. Modifiers of $0.1 \%$ formic acid and $5 \mathrm{mmol} / \mathrm{L}$ ammonium formate in aqueous phase were investigated. The addition of formic acid in aqueous phase resulted in better responses of target mycotoxins since the formic acid could facilitate the protonization of some mycotoxins. Thus, methanol- $0.1 \%$ aqueous formic acid $(v / v)$ was chosen as the mobile phase. The extracted ion chromatograms of mycotoxins were shown in Figure 1.

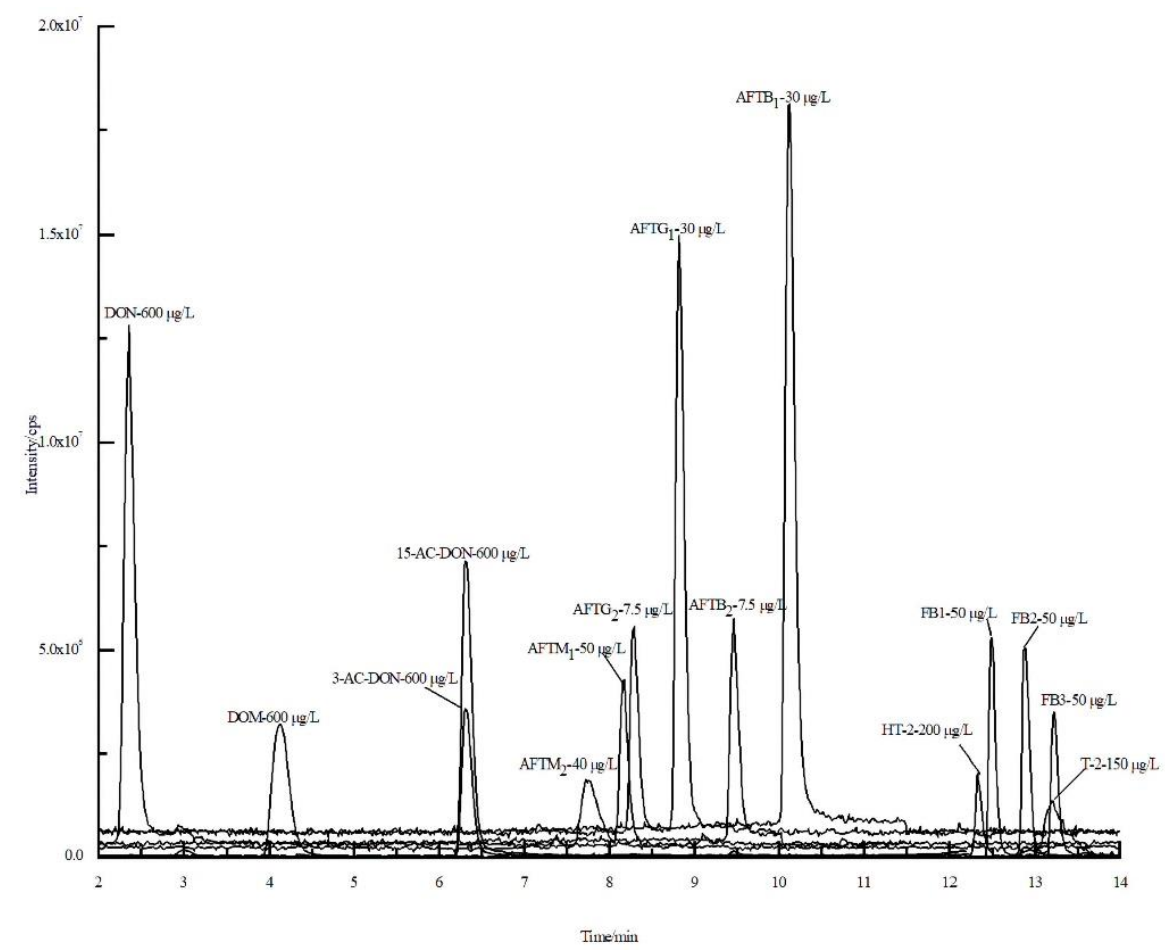

(a)

Figure 1. Cont. 


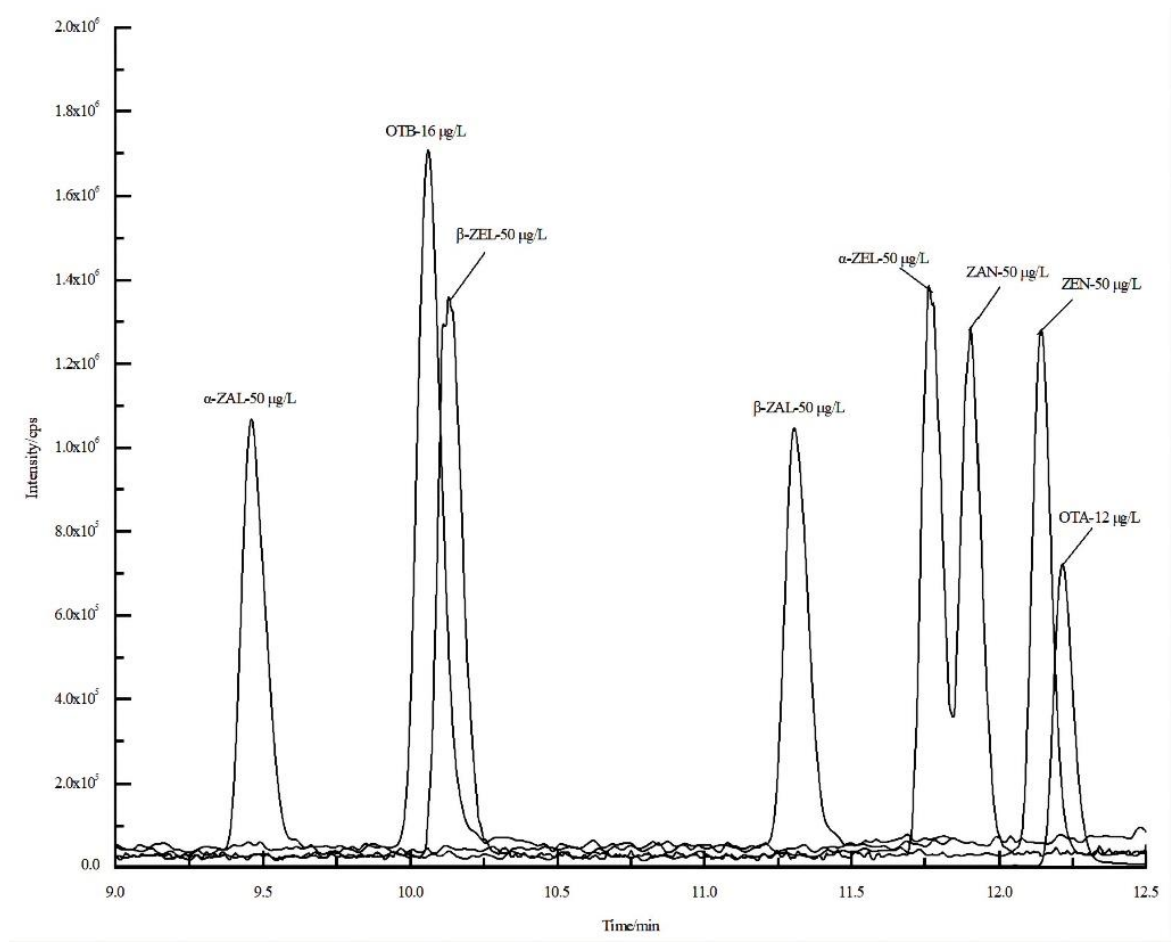

(b)

Figure 1. Extracted ion chromatograms of the 23 mycotoxins at positive mode (a) and negative mode (b).

Different spray voltages of 2.8, 3.0, and $3.5 \mathrm{kV}$ for heated ESI (HESI) were studied for the ionization of targets, illustrating that $3.0 \mathrm{kV}$ led to better ionization efficiency of target compounds. According to accurate identification of HRMS, two ions of mass tolerance within $5 \mathrm{ppm}$ are required. One of these ions is required to be a fragment ion while the second ion should be the (de-) protonated molecular ion or an adduct ion thereof. In this work, full MS/data dependent-MS ${ }^{2}$ (full MS/dd-MS ${ }^{2}$ ) mode would be chosen and would give the information of precursor ions and MS/MS spectra. Retention time, accurate $m / z$ of molecular ion and accurate $\mathrm{m} / \mathrm{z}$ of the fragment were listed in Table 2. Within $14.0 \mathrm{~min}$, satisfactory separation and detection were realized. According to the structure and the properties of mycotoxins, both positive and negative ionization modes were used.

\subsection{The Optimization of SPE Pretreatment}

The extraction solvent directly influenced recoveries of compounds. To obtain higher recoveries and decrease matrix interference, considering characteristics of protein and lipid contents in broiler tissue, different extraction solutions were optimized in order to realize simultaneous extraction of 23 mycotoxins. Methanol/formic acid $(98: 2, v / v)$, acetonitrile/formic acid $(98: 2, v / v)$ and acetonitrile/water/methanol $(80: 18: 2, v / v / v)$ were investigated for preparation of broiler tissues including chicken breast meat, gizzards, and liver. When acidified methanol was used, two phases of solid-liquid could not be well separated, and the extraction solution was also in the muddy state even after centrifugation. However, no such phenomenon would happen when acetonitrile was used. Thus, acidified acetonitrile was used to extract 23 mycotoxins. The recovery comparison of two extraction solutions were shown in Figure 2. Finally, acetonitrile/water/methanol (80:18:2, $v / v / v)$ was selected. 
Table 2. Qualification parameters of 23 mycotoxins.

\begin{tabular}{|c|c|c|c|c|c|}
\hline Comment & Ion Mode & $\begin{array}{l}\text { Measured Mass } \\
(\mathrm{m} / \mathrm{z})\end{array}$ & $\begin{array}{c}\text { Characteristic Ion } \\
1(\mathrm{~m} / \mathrm{z})\end{array}$ & $\begin{array}{l}\text { Characteristic Ion } \\
2(\mathrm{~m} / \mathrm{z})\end{array}$ & $\mathrm{RT} / \mathrm{min}$ \\
\hline $\mathrm{AFB}_{1}$ & {$[\mathrm{M}+\mathrm{H}]^{+}$} & 313.07111 & 285.07611 & 270.05267 & 9.68 \\
\hline $\mathrm{AFB}_{2}$ & {$[\mathrm{M}+\mathrm{H}]^{+}$} & 315.08661 & 287.09186 & 259.06024 & 9.22 \\
\hline $\mathrm{AFG}_{1}$ & {$[\mathrm{M}+\mathrm{H}]^{+}$} & 329.06577 & 243.06554 & 283.06055 & 8.42 \\
\hline $\mathrm{AFG}_{2}$ & {$[\mathrm{M}+\mathrm{H}]^{+}$} & 331.08191 & 313.07135 & 245.08141 & 7.86 \\
\hline $\mathrm{AFM}_{1}$ & {$[\mathrm{M}+\mathrm{H}]^{+}$} & 329.06577 & 273.07593 & 259.06036 & 7.68 \\
\hline $\mathrm{AFM}_{2}$ & {$[\mathrm{M}+\mathrm{H}]^{+}$} & 331.08008 & 273.07608 & 285.07596 & 6.70 \\
\hline $\mathrm{T}-2$ & {$\left[\mathrm{M}+\mathrm{NH}_{4}\right]^{+}$} & 484.25464 & 305.13736 & 185.09566 & 12.34 \\
\hline HT-2 & {$\left[\mathrm{M}+\mathrm{NH}_{4}\right]^{+}$} & 442.24233 & 263.12665 & 235.10591 & 11.90 \\
\hline $\mathrm{FB}_{1}$ & {$[\mathrm{M}+\mathrm{H}]^{+}$} & 722.39337 & 704.38312 & 352.32013 & 11.75 \\
\hline $\mathrm{FB}_{2}$ & {$[\mathrm{M}+\mathrm{H}]^{+}$} & 706.3985 & 336.32513 & 688.38812 & 13.15 \\
\hline $\mathrm{FB}_{3}$ & {$[\mathrm{M}+\mathrm{H}]^{+}$} & 706.3985 & 336.32523 & 688.38812 & 12.82 \\
\hline DON & {$[\mathrm{M}+\mathrm{H}]^{+}$} & 297.13287 & 249.11194 & 203.10658 & 2.35 \\
\hline DOM & {$[\mathrm{M}+\mathrm{H}]^{+}$} & 281.13724 & 235.10661 & 137.05975 & 4.18 \\
\hline 15-ADON & {$[\mathrm{M}+\mathrm{H}]^{+}$} & 339.14368 & 323.12293 & 137.05972 & 6.28 \\
\hline 3-ADON & {$[\mathrm{M}+\mathrm{H}]^{+}$} & 339.14368 & 231.10149 & 279.12253 & 6.28 \\
\hline$\alpha-Z A L$ & {$[\mathrm{M}-\mathrm{H}]^{-}$} & 323.17032 & 277.18048 & 303.15970 & 9.45 \\
\hline$\beta-Z A L$ & {$[\mathrm{M}-\mathrm{H}]^{-}$} & 323.17041 & 277.1806 & 303.15982 & 11.29 \\
\hline$\alpha-\mathrm{ZOL}$ & {$[\mathrm{M}-\mathrm{H}]^{-}$} & 319.15454 & 275.16489 & 160.01656 & 11.76 \\
\hline$\beta-\mathrm{ZOL}$ & {$[\mathrm{M}-\mathrm{H}]^{-}$} & 319.15463 & 275.16495 & 160.01651 & 10.13 \\
\hline ZAN & {$[\mathrm{M}-\mathrm{H}]^{-}$} & 319.1546 & 275.16501 & 205.08682 & 11.91 \\
\hline ZEN & {$[\mathrm{M}-\mathrm{H}]^{-}$} & 317.13907 & 131.05017 & 175.03992 & 12.14 \\
\hline OTA & {$[\mathrm{M}-\mathrm{H}]^{-}$} & 402.07407 & 358.08435 & 231.01634 & 12.23 \\
\hline OTB & {$[\mathrm{M}-\mathrm{H}]^{-}$} & 368.11105 & 324.12436 & 280.09824 & 10.06 \\
\hline
\end{tabular}

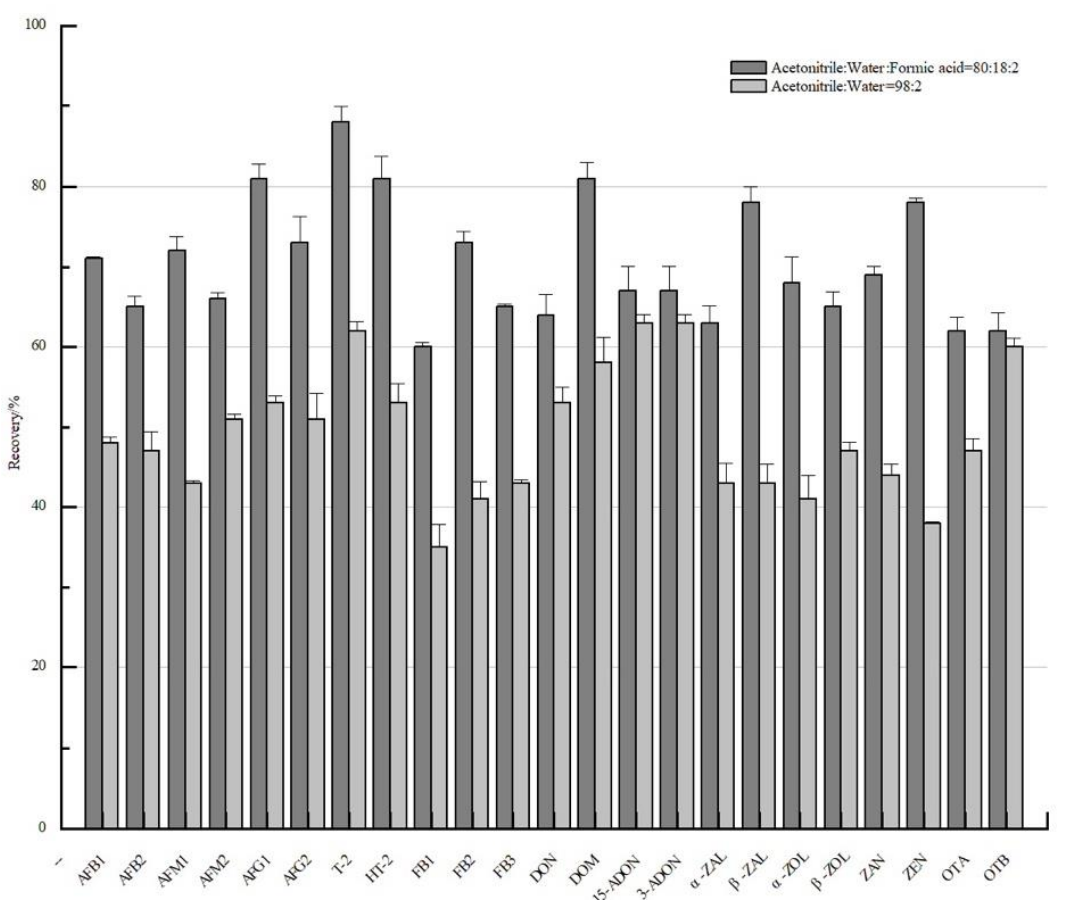

Figure 2. The effect of different extracts on the recovery of each mycotoxin.

Chicken breast meat which was cheap and easily available were widely consumed. Chicken liver and gizzard were the characteristic Chinese food. Considering 1.4 billion Chinese people, the method development was of great importance. As for different matrices of chicken breast meat, liver and gizzard, a great certain of proteins, lipids and minerals would be retained in the extraction solution, which brought in interference to mycotoxin determination. Besides, different mycotoxins would have different physicochemical properties. Therefore, it would be of great necessity to develop the method which would be 
suitable for multiple mycotoxins. In this study, two multifunctional purification cartridges were investigated for the purification effect of 23 mycotoxins, such as Oasis PRIME-HLB and Captiva-EMR Lipid purification cartridges, whose purification effects on mycotoxin recoveries were shown in Figure 3. Both of those two columns allowed direct sample loading without equilibrium and activation and belonging to filtering SPE cartridge for the impurity removal, which greatly simplified the procedures of SPE and effectively decreased sample treatment time [24,25]. Captiva-EMR Lipid purification cartridge also had a higher absorptive capacity and removal efficiency of lipids. According to the response after the purification by Captiva EMR Lipid and Oasis PRIME-HLB cartridges, recoveries of 23 mycotoxins with the pretreatment of Captiva EMP Lipid cartridge were acceptable, namely $61-111 \%$, wherein FBs also demonstrated good results. Thus, in this work, the Captiva-EMR Lipid purification cartridge was chosen.

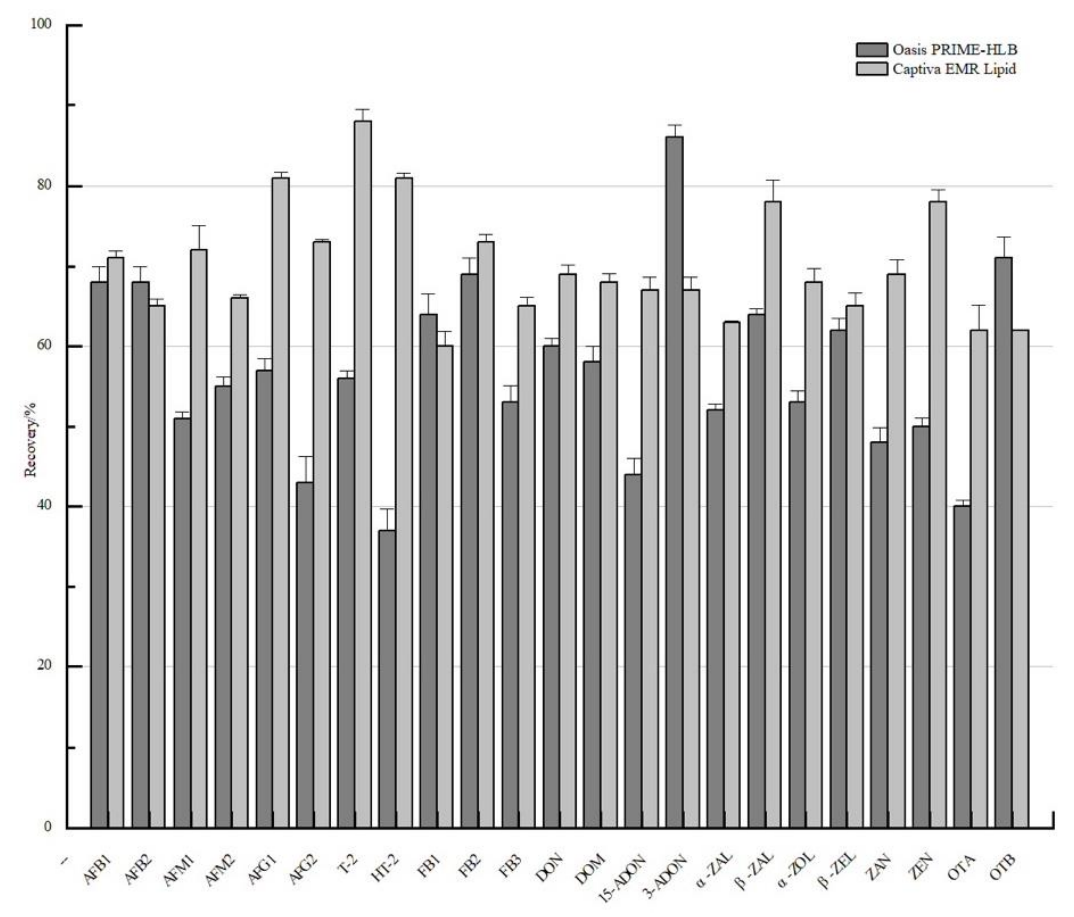

Figure 3. The influence of different purification columns on the recovery of each mycotoxin.

\subsection{Matrix Effect}

The matrix effect was mainly due to endogenous components in the sample as well as impurities introduced in the pretreatment process. In ESI, the response of different mycotoxins was easily influenced by matrices, which was represented by the slope ratio between linear regression equation in blank matrix and that in the solvent. As shown in Table 3, most of the mycotoxins demonstrated relatively strong matrix effect. Thus, the matrix-matched linearity was used in this study to make up for the influence of matrix effect, guaranteeing the stability and accuracy of MS results.

\subsection{The Method Validation}

The recovery and repeatability assays were processed in three different blank matrices (chicken breast meat, liver and gizzard), respectively. And they were investigated at three spiking levels in six replicates. As shown in Table 4, recoveries of 23 mycotoxins were between $61 \%$ and $111 \%$ with RSDs $<15 \%$. The good recovery and repeatability verified that the established SPE-UHPLC Q/orbitrap HRMS method was suitable for routine risk monitoring of 23 mycotoxins in broiler tissues such as breast meat, liver, and gizzards. 
Table 3. Evaluation of matrix effect.

\begin{tabular}{cccc}
\hline \multirow{2}{*}{ Mycotoxins } & & Matrix Effect/\% & \\
\cline { 2 - 4 } & Breast & Gizzard & Liver \\
\hline AFB $_{1}$ & 88.64 & 71.29 & 59.10 \\
$\mathrm{AFB}_{2}$ & 88.14 & 40.46 & 55.95 \\
$\mathrm{AFG}_{1}$ & 90.35 & 62.03 & 85.96 \\
$\mathrm{AFG}_{2}$ & 78.85 & 66.55 & 70.11 \\
$\mathrm{AFM}_{1}$ & 80.98 & 59.78 & 87.02 \\
$\mathrm{AFM}_{2}$ & 87.94 & 55.50 & 87.72 \\
$\mathrm{~T}-2$ & 48.11 & 32.62 & 42.23 \\
$\mathrm{HT}-2$ & 46.24 & 35.27 & 46.98 \\
$\mathrm{FB}$ & 15.96 & 16.00 & 46.82 \\
$\mathrm{FB}_{2}$ & 38.38 & 20.79 & 54.17 \\
$\mathrm{FB}$ & 48.29 & 73.76 & 39.81 \\
$\mathrm{DON}$ & 34.31 & 10.32 & 36.97 \\
$\mathrm{DOM}$ & 90.11 & 76.82 & 67.87 \\
$15-\mathrm{ADON}$ & 87.14 & 63.23 & 57.97 \\
$3-\mathrm{ADON}$ & 87.14 & 58.27 & 62.28 \\
$\alpha-Z A L$ & 21.54 & 40.17 & 23.75 \\
$\beta-Z A L$ & 36.61 & 46.91 & 48.26 \\
$\alpha-Z O L$ & 32.47 & 47.98 & 37.62 \\
$\beta-Z O L$ & 37.78 & 57.52 & 12.29 \\
ZAN & 40.42 & 26.37 & 50.35 \\
ZEN & 44.22 & 44.32 & 44.01 \\
OTA & 30.35 & 32.43 & 58.76 \\
OTB & 49.42 & 32.21 & 29.26 \\
\hline
\end{tabular}

Table 4. Recoveries of 23 mycotoxins at 3 levels $(n=6)$.

\begin{tabular}{|c|c|c|c|c|c|c|c|}
\hline \multirow{2}{*}{ Mycotoxins } & \multirow{2}{*}{$\begin{array}{l}\text { Added Concentration } \\
(\mu \mathrm{g} / \mathrm{kg})\end{array}$} & \multicolumn{2}{|c|}{ Chicken Liver } & \multicolumn{2}{|c|}{ Chicken Gizzard } & \multicolumn{2}{|c|}{ Chicken Breast Meat } \\
\hline & & Recovery/\% & RSD $/ \%$ & Recovery $/ \%$ & RSD/\% & Recovery $/ \%$ & $\mathrm{RSD} / \%$ \\
\hline \multirow{3}{*}{$\mathrm{AFB}_{1}$} & 7.5 & 85 & 0.3 & 64 & 0.8 & 67 & 10.1 \\
\hline & 15 & 67 & 5.4 & 65 & 1.7 & 79 & 9.0 \\
\hline & 37.5 & 69 & 11.9 & 69 & 0.4 & 80 & 5.0 \\
\hline \multirow{3}{*}{$\mathrm{AFB}_{2}$} & 1.875 & 68 & 1.3 & 62 & 2.4 & 101 & 3.6 \\
\hline & 3.75 & 65 & 2.6 & 68 & 3.2 & 77 & 10.9 \\
\hline & 9.375 & 73 & 7.6 & 81 & 1.4 & 69 & 3.9 \\
\hline \multirow{3}{*}{$\mathrm{AFG}_{1}$} & 7.5 & 61 & 1.8 & 84 & 0.3 & 73 & 2.8 \\
\hline & 15 & 62 & 3.4 & 71 & 1.5 & 84 & 8.6 \\
\hline & 37.5 & 61 & 1.7 & 61 & 1.7 & 70 & 8.6 \\
\hline \multirow{3}{*}{$\mathrm{AFG}_{2}$} & 1.875 & 69 & 0.8 & 67 & 0.6 & 67 & 1.3 \\
\hline & 3.75 & 67 & 4.1 & 61 & 1.3 & 72 & 10.5 \\
\hline & 9.375 & 63 & 4.1 & 66 & 12.5 & 73 & 5.5 \\
\hline \multirow{3}{*}{$\mathrm{AFM}_{1}$} & 12.5 & 67 & 1.7 & 70 & 0.9 & 64 & 2.0 \\
\hline & 25 & 92 & 3.1 & 66 & 5.1 & 65 & 8.1 \\
\hline & 62.5 & 65 & 3.3 & 68 & 3.2 & 63 & 4.1 \\
\hline \multirow{3}{*}{$\mathrm{AFM}_{2}$} & 10 & 78 & 3.3 & 87 & 6.2 & 63 & 2.0 \\
\hline & 20 & 91 & 1.3 & 89 & 8.9 & 62 & 2.0 \\
\hline & 50 & 88 & 5.4 & 82 & 3.6 & 66 & 6.1 \\
\hline \multirow{3}{*}{$\mathrm{T}-2$} & 37.5 & 75 & 5.9 & 80 & 9.2 & 70 & 10.9 \\
\hline & 75 & 97 & 9.4 & 67 & 12.6 & 67 & 9.0 \\
\hline & 187.5 & 67 & 2.4 & 67 & 4.1 & 75 & 4.0 \\
\hline
\end{tabular}


Table 4. Cont.

\begin{tabular}{|c|c|c|c|c|c|c|c|}
\hline \multirow{2}{*}{ Mycotoxins } & \multirow{2}{*}{$\begin{array}{l}\text { Added Concentration } \\
(\mu \mathrm{g} / \mathrm{kg})\end{array}$} & \multicolumn{2}{|c|}{ Chicken Liver } & \multicolumn{2}{|c|}{ Chicken Gizzard } & \multicolumn{2}{|c|}{ Chicken Breast Meat } \\
\hline & & Recovery/\% & RSD/\% & Recovery/\% & $\mathrm{RSD} / \%$ & Recovery/\% & $\mathrm{RSD} / \%$ \\
\hline \multirow{3}{*}{ HT-2 } & 52.5 & 87 & 2.7 & 75 & 2.4 & 87 & 2.3 \\
\hline & 105 & 75 & 8.2 & 88 & 4.1 & 71 & 13.5 \\
\hline & 262.5 & 93 & 3.1 & 86 & 3.4 & 72 & 3.5 \\
\hline \multirow{3}{*}{$\mathrm{FB}_{1}$} & 12.5 & 69 & 0.5 & 62 & 2.9 & 66 & 3.4 \\
\hline & 25 & 73 & 3.0 & 77 & 1.2 & 65 & 7.2 \\
\hline & 62.5 & 75 & 6.9 & 81 & 6.2 & 77 & 4.2 \\
\hline \multirow{3}{*}{$\mathrm{FB}_{2}$} & 12.5 & 102 & 1.4 & 66 & 2.2 & 64 & 8.0 \\
\hline & 25 & 68 & 3.9 & 67 & 3.6 & 64 & 6.5 \\
\hline & 62.5 & 87 & 2.2 & 86 & 6.0 & 72 & 7.5 \\
\hline \multirow{3}{*}{$\mathrm{FB}_{3}$} & 12.5 & 64 & 4.4 & 65 & 1.4 & 64 & 6.9 \\
\hline & 25 & 76 & 9.5 & 69 & 0.3 & 65 & 9.7 \\
\hline & 62.5 & 66 & 5.1 & 64 & 4.9 & 65 & 7.7 \\
\hline \multirow{3}{*}{$\mathrm{DON}$} & 350 & 67 & 1.2 & 64 & 2.6 & 66 & 1.1 \\
\hline & 700 & 68 & 2.8 & 67 & 3.8 & 68 & 7.9 \\
\hline & 1750 & 67 & 2.7 & 69 & 4.6 & 76 & 5.8 \\
\hline \multirow{3}{*}{ DOM } & 300 & 65 & 1.8 & 66 & 1.3 & 65 & 1.4 \\
\hline & 600 & 67 & 3.6 & 81 & 1.9 & 81 & 7.8 \\
\hline & 1500 & 75 & 1.1 & 75 & 2.1 & 69 & 1.0 \\
\hline \multirow{3}{*}{$15-\mathrm{ADON}$} & 300 & 63 & 3.1 & 69 & 1.1 & 94 & 9.2 \\
\hline & 600 & 68 & 7.9 & 74 & 3.1 & 111 & 5.3 \\
\hline & 1500 & 68 & 3.2 & 69 & 5.3 & 71 & 4.3 \\
\hline \multirow{3}{*}{ 3-ADON } & 300 & 63 & 3.1 & 69 & 1.1 & 93 & 3.1 \\
\hline & 600 & 68 & 7.9 & 73 & 3.1 & 111 & 5.8 \\
\hline & 1500 & 68 & 3.2 & 69 & 5.3 & 78 & 3.8 \\
\hline \multirow{3}{*}{$\alpha-\mathrm{ZAL}$} & 12.5 & 95 & 2.1 & 77 & 2.5 & 67 & 7.3 \\
\hline & 25 & 64 & 5.3 & 87 & 1.1 & 86 & 5.1 \\
\hline & 62.5 & 86 & 1.6 & 88 & 2.7 & 63 & 4.1 \\
\hline \multirow{3}{*}{$\beta-Z A L$} & 12.5 & 94 & 2.0 & 76 & 2.4 & 65 & 6.6 \\
\hline & 25 & 66 & 5.3 & 87 & 1.1 & 80 & 3.8 \\
\hline & 62.5 & 83 & 1.5 & 88 & 2.5 & 62 & 3.8 \\
\hline \multirow{3}{*}{$\alpha-\mathrm{ZOL}$} & 12.5 & 86 & 3.2 & 83 & 3.0 & 62 & 4.5 \\
\hline & 25 & 64 & 2.3 & 85 & 1.3 & 72 & 5.5 \\
\hline & 62.5 & 66 & 2.0 & 81 & 1.8 & 64 & 6.5 \\
\hline \multirow{3}{*}{$\beta-\mathrm{ZOL}$} & 12.5 & 71 & 1.9 & 79 & 3.1 & 66 & 8.4 \\
\hline & 25 & 75 & 9.4 & 95 & 1.0 & 83 & 6.7 \\
\hline & 62.5 & 87 & 3.4 & 95 & 0.8 & 65 & 5.7 \\
\hline \multirow{3}{*}{ ZAN } & 12.5 & 76 & 5.1 & 85 & 2.4 & 64 & 7.7 \\
\hline & 25 & 71 & 10.0 & 69 & 2.0 & 76 & 5.5 \\
\hline & 62.5 & 72 & 4.0 & 69 & 1.9 & 62 & 3.5 \\
\hline \multirow{3}{*}{ ZEN } & 12.5 & 84 & 0.6 & 78 & 0.2 & 64 & 5.0 \\
\hline & 25 & 96 & 2.1 & 68 & 0.4 & 77 & 3.6 \\
\hline & 62.5 & 79 & 8.2 & 71 & 0.6 & 68 & 4.6 \\
\hline \multirow{3}{*}{ OTA } & 3 & 83 & 3.7 & 74 & 3.5 & 70 & 6.5 \\
\hline & 6 & 69 & 3.7 & 102 & 2.3 & 85 & 5.5 \\
\hline & 15 & 95 & 5.1 & 61 & 1.4 & 66 & 7.5 \\
\hline & 3.75 & 66 & 2.3 & 66 & 1.1 & 77 & 6.1 \\
\hline ОтВ & 7.5 & 66 & 8.1 & 73 & 0.9 & 72 & 5.7 \\
\hline & 18.75 & 70 & 5.9 & 71 & 0.7 & 89 & 4.7 \\
\hline
\end{tabular}


Mixed standard solutions of mycotoxins with different concentrations were obtained in blank matrix solution. The linear regression equation was plotted through y of peak area and $x$ of concentration $(\mu \mathrm{g} / \mathrm{L})$ as shown in Table 5. Linearity of 23 mycotoxins with correlation coefficients $\left(\mathrm{R}^{2}\right)$ larger than 0.991 was obtained. LODs were in the range of $0.40-130.00 \mu \mathrm{g} / \mathrm{kg}$ and LOQs ranged from 1.20 to $350.00 \mu \mathrm{g} / \mathrm{kg}$ in those three matrices.

\subsection{The Real Sample Analysis}

With the optimized method, 30 samples including breast meat, liver and gizzard purchased from different markets were determined. ZEN was detected in one of chicken liver samples with the concentration of $15.29 \mu \mathrm{g} / \mathrm{kg}$. Other samples' determination results were below the corresponding LOD. The MS/MS spectra of ZEN in the contaminated liver sample was shown in Figure 4. The occurrence of the positive result was due to the polluted feeds, which resulted in mycotoxin residue in animal. In addition, the pollution during the processing, storage, and marketing processes of meat was also possible.

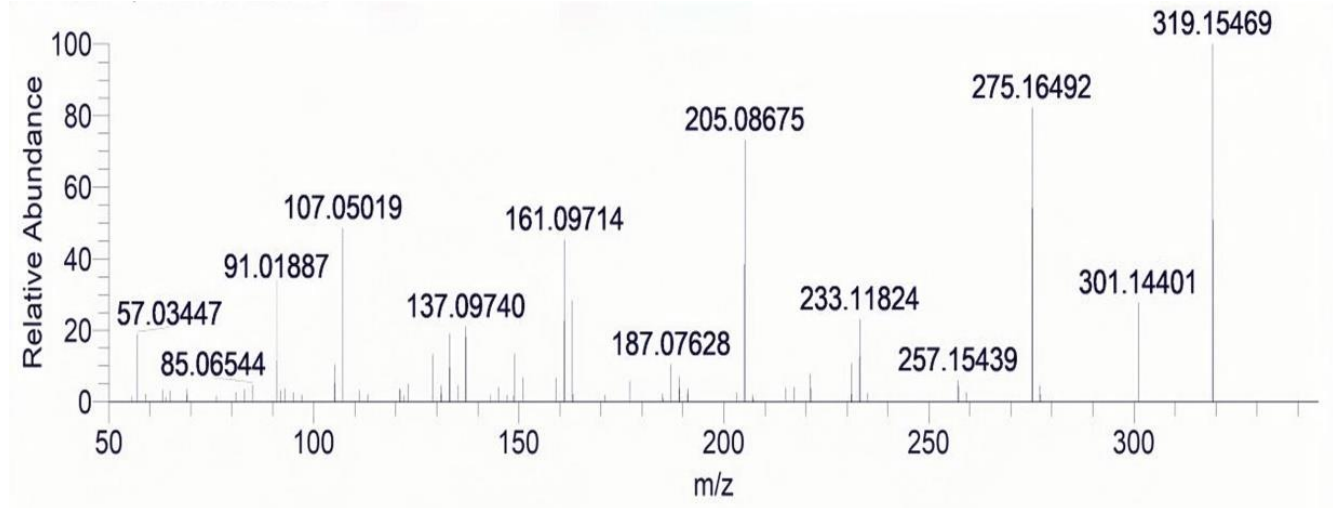

(a)

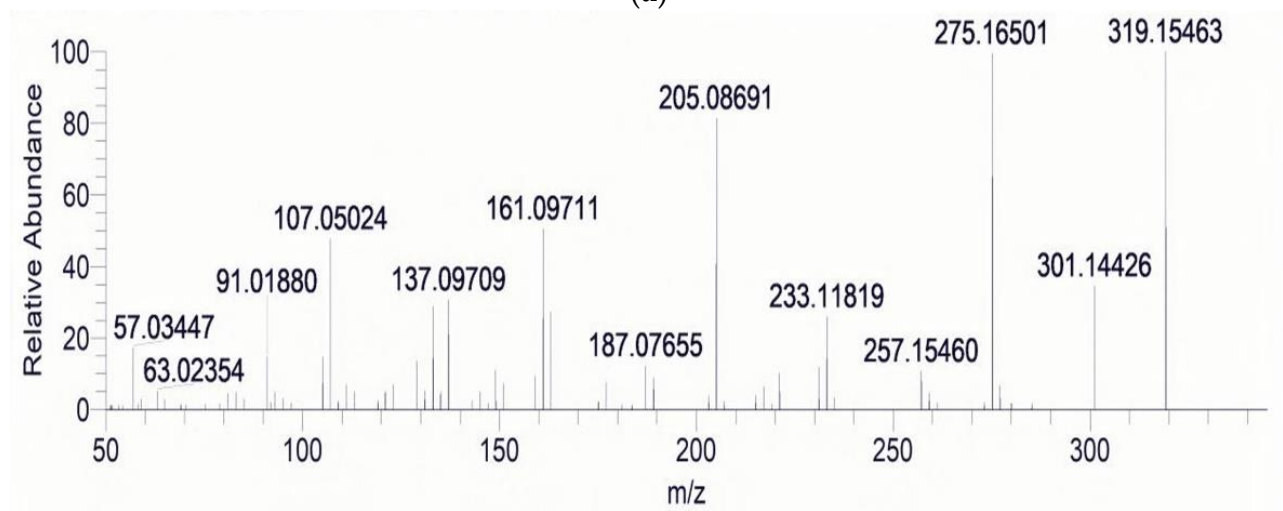

(b)

Figure 4. MS ${ }^{2}$ spectra of ZEN in the standard solution (a) and contaminated sample (b).

ZEN was one of the most important mycotoxins, which altered fertility and reproduction and influenced hepatic cellular immune response. After oral administration, ZEN was difficult to be detected in vivo, which was not appropriate as the biomarker. However, in this work, ZEN's concentration in the positive liver sample was relatively high, illustrating that liver was the target organ reported in some publications. Besides, in the risk assessment report of ZEN from European Food Scientific Agency (EFSA) in 2011, the tolerable daily intake (TDI) was $0.25 \mu \mathrm{g} / \mathrm{kg}$ body weight. According to the adult body weight of $60 \mathrm{~kg}$, although the ZEN intake of this positive liver sample didn't exceed the standard, the long-term or large dose intake hazards had to be worried especially considering those susceptible groups such as pregnant women or children. 
Table 5. Linear range, detection limit and quantification limit of 23 mycotoxins.

\begin{tabular}{|c|c|c|c|c|c|c|c|c|c|c|c|c|c|c|c|}
\hline \multirow[b]{2}{*}{ Mycotoxins } & \multicolumn{5}{|c|}{ Chicken Breast } & \multicolumn{5}{|c|}{ Chicken Gizzard } & \multicolumn{5}{|c|}{ Chicken Liver } \\
\hline & $\begin{array}{c}\text { Linear Range } \\
(\mu \mathrm{g} / \mathrm{L})\end{array}$ & Linear Equation & $\begin{array}{c}\text { Correlation } \\
\text { Coefficient (R2) }\end{array}$ & $\begin{array}{l}\mathrm{LOD} \\
(\mu \mathrm{g} / \mathrm{kg})\end{array}$ & $\begin{array}{c}\mathrm{LOO} \\
(\mu \mathrm{g} / \mathrm{kg})\end{array}$ & $\begin{array}{c}\text { Linear Range } \\
(\mu \mathrm{g} / \mathrm{L})\end{array}$ & Linear Equation & $\begin{array}{c}\text { Correlation } \\
\text { Coofficient (R2) }\end{array}$ & $\begin{array}{l}\mathrm{LOD} \\
(\mu \mathrm{g} / \mathrm{kg})\end{array}$ & $\begin{array}{c}\mathrm{LOO} \\
(\mu \mathrm{g} / \mathrm{kg})\end{array}$ & $\begin{array}{c}\text { Linear Range } \\
(\mu \mathrm{g} / \mathrm{L})\end{array}$ & Linear Equation & $\begin{array}{c}\text { Correlation } \\
\text { Coefficient (R2) }\end{array}$ & $\begin{array}{l}\mathrm{LOD} \\
(\mu \mathrm{g} / \mathrm{kg})\end{array}$ & $\begin{array}{c}\mathrm{LOO} \\
(\mu \mathrm{g} / \mathrm{kg}) \\
\end{array}$ \\
\hline $\mathrm{AFB}_{1}$ & $15-600$ & $Y=1.774 \times 10^{7} X+1.826 \times 10^{8}$ & 0.994 & 2.5 & 7.5 & $10-400$ & $Y=6.18 \times 10^{7} X-5.973 \times 10^{7}$ & 0.994 & 2 & 6 & $10-400$ & $Y=1.115 \times 10^{7} X+1.125 \times 10^{8}$ & 0.99 & 1.6 & 5 \\
\hline $\mathrm{AFB}_{2}$ & 3.75-150 & $\mathrm{Y}=3.381 \times 10^{6} \mathrm{X}+2.306 \times 10^{6}$ & 0.999 & 0.6 & 1.8 & $2.5-100$ & $Y=5.679 \times 10^{6} x-1.568 \times 10^{7}$ & 0.995 & 0.5 & 1.5 & $2.5-100$ & $Y=2.18 \times 10^{6} X-5.715 \times 10^{6}$ & 0.999 & 0.4 & 1.2 \\
\hline $\mathrm{AFG}_{1}$ & $15-600$ & $Y=1.189 \times 10^{7} X+4.353 \times 10^{6}$ & 0.999 & 2.5 & 7.5 & $10-400$ & $Y=7.338 \times 10^{6} x-1.415 \times 10^{7}$ & 0.998 & 2 & 6 & $10-400$ & $Y=8.478 \times 10^{6} X+7.596 \times 10^{7}$ & 0.993 & 2 & 6 \\
\hline $\mathrm{AFG}_{2}$ & 3.75-150 & $Y=2.401 \times 10^{7} X-3.781 \times 10^{4}$ & 0.999 & 0.6 & 1.8 & $2.5-100$ & $Y=7.178 \times 10^{7} X-1.472 \times 10^{7}$ & 0.995 & 0.5 & 1.5 & $2.5-100$ & $Y=8.034 \times 10^{6} X+1.568 \times 10^{7}$ & 0.994 & 0.5 & 1.5 \\
\hline $\mathrm{AFM}_{1}$ & 25-1000 & $Y=1.189 \times 10^{7} X+2.323 \times 10^{7}$ & 0.999 & 4.1 & 12.5 & $12.5-500$ & $\mathrm{Y}=2.956 \times 10^{7} \mathrm{X}-1.481 \times 10^{7}$ & 0.997 & 3 & 9 & $25-1000$ & $Y=9.161 \times 10^{6} X-3.877 \times 10^{7}$ & 0.998 & 4.1 & 12.5 \\
\hline $\mathrm{AFM}_{2}$ & $20-800$ & $Y=3.995 \times 10^{6} \mathrm{X}+3.346 \times 10^{6}$ & 0.999 & 3.33 & 10 & $10-400$ & $Y=8.977 \times 10^{6} X-9.662 \times 10^{4}$ & 0.998 & 2.6 & 8 & $20-800$ & $Y=3.253 \times 10^{6} \mathrm{X}-1.48 \times 10^{7}$ & 0.999 & 3.33 & 10 \\
\hline $\mathrm{T}-2$ & 75-3000 & $\mathrm{Y}=5.261 \times 10^{6} \mathrm{X}-8.745 \times 10^{5}$ & 0.999 & 12.5 & 37.5 & 37-1500 & $Y=3.966 \times 10^{6} X+6.703 \times 10^{6}$ & 0.999 & 11 & 33 & 75-3000 & $Y=3.699 \times 10^{6} \mathrm{X}+3.321 \times 10^{6}$ & 0.99 & 12.5 & 37.5 \\
\hline HT-2 & $105-4200$ & $Y=6.596 \times 10^{5} X-4.328 \times 10^{5}$ & 0.999 & 17.5 & 52.5 & 52-2100 & $Y=1.019 \times 10^{6} X-9.894 \times 10^{5}$ & 0.992 & 16 & 48 & $105-4200$ & $Y=1.244 \times 10^{6} X-1.584 \times 10^{6}$ & 0.999 & 17.5 & 52.5 \\
\hline $\mathrm{FB}_{1}$ & $12.5-500$ & $Y=1.496 \times 10^{7} X-2.147 \times 10^{7}$ & 0.997 & 3 & 9 & $12.5-500$ & $Y=1.781 \times 10^{7} X-2.425 \times 10^{7}$ & 0.99 & 3 & 9 & 25-1000 & $Y=2.81 \times 10^{7} X-1.435 \times 10^{7}$ & 0.995 & 4.17 & 12.5 \\
\hline $\mathrm{FB}_{2}$ & $12.5-500$ & $Y=1.239 \times 10^{7} X-1.408 \times 10^{7}$ & 0.997 & 3 & 9 & $12.5-500$ & $Y=1.539 \times 10^{7} X-1.507 \times 10^{7}$ & 0.994 & 3.3 & 10 & 25-1000 & $Y=2.66 \times 10^{6} X-1.205 \times 10^{7}$ & 0.992 & 4.17 & 12.5 \\
\hline $\mathrm{FB}_{3}$ & $12.5-500$ & $Y=1.781 \times 10^{7} X-1.608 \times 10^{7}$ & 0.999 & 3 & 9 & $12.5-500$ & $Y=4.025 \times 10^{7} X+2.219 \times 10^{7}$ & 0.994 & 3.3 & 10 & 25-1000 & $\mathrm{Y}=2.959 \times 10^{6} \mathrm{X}+941 \times 10^{6}$ & 0.997 & 4.17 & 12.5 \\
\hline DON & $700-28,000$ & $Y=1.773 \times 10^{5} X+1.106 \times 10^{8}$ & 0.991 & 130 & 350 & $350-14,000$ & $Y=1.986 \times 10^{5} X+1.826 \times 10^{8}$ & 0.993 & 100 & 300 & $700-28,000$ & $Y=2.81 \times 10^{5} X+3.715 \times 10^{7}$ & 0.994 & 130 & 350 \\
\hline DOM & $600-24,000$ & $\mathrm{Y}=7.032 \times 10^{5} \mathrm{X}+4.598 \times 10^{8}$ & 0.996 & 100 & 300 & $300-12,000$ & $\mathrm{Y}=3.986 \times 10^{5} \mathrm{X}+2.436 \times 10^{8}$ & 0.995 & 93 & 280 & $300-12,000$ & $\mathrm{Y}=4.19 \times 10^{5} \mathrm{X}+2.715 \times 10^{8}$ & 0.991 & 93 & 280 \\
\hline 15-AC-DON & $600-24,000$ & $Y=3.089 \times 10^{6} X+1.774 \times 10^{8}$ & 0.999 & 100 & 300 & $300-12,000$ & $Y=8.444 \times 10^{6} X+3.126 \times 10^{7}$ & 0.993 & 93 & 280 & $300-12,000$ & $\mathrm{Y}=7.35 \times 10^{6} \mathrm{X}+5.715 \times 10^{7}$ & 0.992 & 93 & 280 \\
\hline 3-AC-DON & $600-24,000$ & $Y=3.089 \times 10^{6} X+1.774 \times 10^{8}$ & 0.999 & 100 & 300 & $300-12,000$ & $Y=7.544 \times 10^{6} X+3.126 \times 10^{7}$ & 0.993 & 93 & 280 & $300-12,000$ & $Y=8.19 \times 10^{6} X+5.715 \times 10^{7}$ & 0.996 & 93 & 280 \\
\hline$\alpha-Z A L$ & $12.5-500$ & $Y=1.464 \times 10^{7} X-4.241 \times 10^{7}$ & 0.993 & 3.75 & 11 & $25-1000$ & $\mathrm{Y}=2.452 \times 10^{7} \mathrm{X}-2.507 \times 10^{7}$ & 0.99 & 4.1 & 12.5 & $12.5-500$ & $Y=1.183 \times 10^{7} X+1.52 \times 10^{6}$ & 0.999 & 3.75 & 11 \\
\hline$\alpha$-ZEL & $12.5-500$ & $Y=2.086 \times 10^{7} X-6.629 \times 10^{7}$ & 0.993 & 3 & 9 & 25-1000 & $Y=4.01 \times 10^{7} X-1.722 \times 10^{7}$ & 0.999 & 4.1 & 12.5 & $12.5-500$ & $\mathrm{Y}=3.344 \times 10^{0} \mathrm{X}-2.162 \times 10^{7}$ & 0.993 & 3.75 & 11 \\
\hline$\beta$-ZEL & $12.5-500$ & $Y=1.891 \times 10^{7} X-5.887 \times 10^{7}$ & 0.992 & 3 & 9 & 25-1000 & $Y=4.45 \times 10^{7} X-1.826 \times 10^{2} 6$ & 0.994 & 4.1 & 12.5 & $12.5-500$ & $Y=2.156 \times 10^{7} X-3.531 \times 10^{7}$ & 0.991 & 3.75 & 11 \\
\hline ZAN & $12.5-500$ & $Y=2.555 \times 10^{7} X-7.456 \times 10^{7}$ & 0.993 & 3 & 9 & 25-1000 & $Y=3.474 \times 10^{7} X-1.004 \times 10^{8}$ & 0.995 & 4.1 & 12.5 & $12.5-500$ & $Y=5.146 \times 10^{7} X-2.078 \times 10^{6}$ & 0.997 & 3.75 & 11 \\
\hline ZEN & $12.5-500$ & $Y=2.361 \times 10^{7} X-6.68 \times 10^{7}$ & 0.994 & 3 & 9 & 25-1000 & $Y=1.636 \times 10^{7} X-5.971 \times 10^{7}$ & 0.9958 & 4.1 & 12.5 & $12.5-500$ & $Y=4.224 \times 10^{7} X-3.686 \times 10^{6}$ & 0.9956 & 3.75 & 11 \\
\hline OTA & 3-240 & $Y=4.359 \times 10^{6} x-7.068 \times 10^{6}$ & 0.992 & 0.6 & 2 & $3-240$ & $Y=6.459 \times 10^{6} X-4.288 \times 10^{6}$ & 0.9989 & 0.6 & 2 & $6-480$ & $Y=1.057 \times 10^{7} X-8.878 \times 10^{25}$ & 0.9926 & 1 & 3 \\
\hline Отв & $7.5-600$ & $Y=4.373 \times 10^{6} X-1.36 \times 10^{7}$ & 0.991 & 1.25 & 3.75 & $3.75-300$ & $Y=6.785 \times 10^{6} \mathrm{X}-1.826 \times 10^{6}$ & 0.9943 & 1 & 3 & $3.75-300$ & $\mathrm{Y}=3.38 \times 10^{6} \mathrm{X}-5.715 \times 10^{26}$ & 0.9918 & 1 & 3 \\
\hline
\end{tabular}


Thus, to ensure the quality of broiler tissue, besides the safeguard of broiler feeds, the possible mycotoxin pollution of broiler in the slaughter or storage process should also be paid attention to.

\section{Conclusions}

An SPE-UHPLC Q/orbitrap method was established for rapid screening, accurate identification and quantitation of 23 mycotoxins in broiler tissues. The screening database of 23 mycotoxins was established, including retention time, accurate precursor $m / z$ and MS/MS fragment, and could facilitate the rapid screening of mycotoxins. In this work, new multi-functional EMR column was applied in the removal of the lipids. Good recoveries were obtained and were in the range of $61-111 \%$. In addition, high accuracy and high anti-interference capacity could be achieved in this method. ZEN at the concentration of $15 \mu \mathrm{g} / \mathrm{kg}$ was detected in one liver sample among 30 real broiler meat and organ samples, showing the possible harmful effect on the target organ of liver.

Author Contributions: Conceptualization, Y.Y. and Y.X.; Methodology, Y.Y., Z.H. and L.M.; Project administration, Y.X. and Y.Y.; Supervision, Y.X. and L.W.; Validation, Z.H.; Writing-original draft, Z.H.; Writing-review \& editing, Y.Y. All authors have read and agreed to the published version of the manuscript.

Funding: This work was funded by the Ministry of Science and Technology of the People's Republic of China (Granted by No. 2017YFC1601600).

Conflicts of Interest: The authors declare that they have no financial or personal relationships with other people or organizations that could inappropriately influence the work in this study.

\section{References}

1. Wang, L.; Zhang, Q.; Yan, Z.; Tan, Y.; Zhu, R.; Yu, D.; Yang, H.; Wu, A. Occurrence and Quantitative Risk Assessment of Twelve Mycotoxins in Eggs and Chicken Tissues in China. Toxins 2018, 10, 477. [CrossRef]

2. Zhu, R.; Zhao, Z.; Wang, J.; Bai, B.; Wu, A.; Yan, L.; Song, S. A simple sample pretreatment method for multi-mycotoxin determination in eggs by liquid chromatography tandem mass spectrometry. J. Chromatogr. A 2015, 1417, 1-7. [CrossRef] [PubMed]

3. Wang, Q.; Zhang, Y.; Zheng, N.; Guo, L.; Song, X.; Zhao, S.; Wang, J. Biological System Responses of Dairy Cows to Aflatoxin B1 Exposure Revealed with Metabolomic Changes in Multiple Biofluids. Toxins 2019, 11, 77. [CrossRef] [PubMed]

4. Iqbal, S.Z.; Nisar, S.; Asi, M.R.; Jinap, S. Natural incidence of aflatoxins, ochratoxin A and zearalenone in chicken meat and eggs. Food Control 2014, 43, 98-103. [CrossRef]

5. Zhao, Z.; Liu, N.; Yang, L.; Deng, Y.; Wang, J.; Song, S.; Lin, S.; Wu, A.; Zhou, Z.; Hou, J. Multi-mycotoxin analysis of animal feed and animal-derived food using LC-MS/MS system with timed and highly selective reaction monitoring. Anal. Bioanal. Chem. 2015, 407, 7359-7368. [CrossRef]

6. Mazur-Kuśnirek, M.; Antoszkiewicz, Z.; Lipiński, K.; Fijałkowska, M.; Purwin, C.; Kotlarczyk, S. The effect of polyphenols and vitamin $\mathrm{E}$ on the antioxidant status and meat quality of broiler chickens fed diets naturally contaminated with ochratoxin A. Arch. Anim. Nutr. 2019, 73, 431-444. [CrossRef] [PubMed]

7. Emmanuel, K.T.; Els, V.P.; Bart, H.; Evelyne, D.; Els, D. Carry-over of some Fusarium mycotoxins in tissues and eggs of chickens fed experimentally mycotoxin-contaminated diets. Food Chem. Toxicol. 2020, 145, 111715. [CrossRef]

8. Buranatragool, K.; Poapolathep, S.; Isariyodom, S.; Imsilp, K.; Klangkaew, N.; Poapolathep, A. Dispositions and tissue residue of zearalenone and its metabolites $\alpha$-zearalenol and $\beta$-zearalenol in broilers. Toxicol. Rep. 2015, 2, 351-356. [CrossRef]

9. Yan, Z.; Wang, L.; Wang, J.; Tan, Y.; Yu, D.; Chang, X.; Fan, Y.; Zhao, D.; Wang, C.; De Boevre, M.; et al. A QuEChERS-Based Liquid Chromatography-Tandem Mass Spectrometry Method for the Simultaneous Determination of Nine Zearalenone-Like Mycotoxins in Pigs. Toxins 2018, 10, 129. [CrossRef]

10. Cui, X.; Muhammad, I.; Li, R.; Jin, H.; Guo, Z.; Yang, Y.; Hamid, S.; Li, J.; Cheng, P.; Zhang, X. Development of a UPLC-FLD Method for Detection of Aflatoxin B1 and M1 in Animal Tissue to Study the Effect of Curcumin on Mycotoxin Clearance Rates. Front. Pharmacol. 2017, 8, 650. [CrossRef]

11. D'Agnello, P.; Vita, V.; Franchino, C.; Urbano, L.; Curiale, A.; Debegnach, F.; Iammarino, M.; Marchesani, G.; Chiaravalle, A.; Pace, R. ELISA and UPLC/FLD as Screening and ConfirmatoryTechniques for T-2/Ht-2 Mycotoxin Determination in Cereals. Appl. Sci. 2021, 11, 1688. [CrossRef]

12. McMaster, N.; Acharya, B.; Harich, K.; Grothe, J.; Mehl, H.L.; Schmale, D.G. Quantification of the Mycotoxin Deoxynivalenol (DON) in Sorghum Using GC-MS and a Stable Isotope Dilution Assay (SIDA). Food Anal. Methods 2019, 12, 2334-2343. [CrossRef]

13. Rodríguez-Carrasco, Y.; Moltó, J.C.; Mañes, J.; Berrada, H. Exposure assessment approach through mycotoxin/creatinine ratio evaluation in urine by GC-MS/MS. Food Chem. Toxicol. 2014, 72, 69-75. [CrossRef] 
14. Turkmen, Z.; Kurada, O. Rapid HPTLC determination of patulin in fruit-based baby food in Turkey. JPC-J. Planar Chromatogr.Mod. TLC 2020, 33, 209-217. [CrossRef]

15. Tkaczyk, A.; Jedziniak, P. Development of a multi-mycotoxin LC-MS/MS method for the determination of biomarkers in pig urine. Mycotoxin Res. 2021, 37, 169-181. [CrossRef] [PubMed]

16. Li, N.; Qiu, J.; Qian, Y. Polyethyleneimine-modified magnetic carbon nanotubes as solid-phase extraction adsorbent for the analysis of multi-class mycotoxins in milk via liquid chromatography-tandem mass spectrometry. J. Sep. Sci. 2020, 44, 636-644. [CrossRef] [PubMed]

17. Steiner, D.; Malachová, A.; Sulyok, M.; Krska, R. Challenges and future directions in LC-MS-based multiclass method development for the quantification of food contaminants. Anal. Bioanal. Chem. 2020, 413, 25-34. [CrossRef] [PubMed]

18. den Hollander, D.; Croubels, S.; Lauwers, M.; Caekebeke, N.; Ringenier, M.; De Meyer, F.; Reisinger, N.; Van Immerseel, F.; Dewulf, J.; Antonissen, G. Applied Research Note: Biomonitoring of mycotoxins in blood serum and feed to assess exposure of broiler chickens. J. Appl. Poult. Res. 2020, 30, 100111. [CrossRef]

19. Nakhjavan, B.; Ahmed, N.S.; Khosravifard, M. Development of an Improved Method of Sample Extraction and Quantitation of Multi-Mycotoxin in Feed by LC-MS/MS. Toxins 2020, 12, 462. [CrossRef] [PubMed]

20. Castaldo, L.; Graziani, G.; Gaspari, A.; Izzo, L.; Tolosa, J.; Rodríguez-Carrasco, Y.; Ritieni, A. Target Analysis and Retrospective Screening of Multiple Mycotoxins in Pet Food Using UHPLC-Q-Orbitrap HRMS. Toxins 2019, 11, 434. [CrossRef]

21. Sun, F.; Tan, H.; Li, Y.; De Boevre, M.; Zhang, H.; Zhou, J.; Li, Y.; Yang, S. An integrated data-dependent and data-independent acquisition method for hazardous compounds screening in foods using a single UHPLC-Q-Orbitrap run. J. Hazard. Mater. 2020, 401, 123266. [CrossRef] [PubMed]

22. Zhou, H.; Cao, Y.-M.; Miao, S.; Lan, L.; Chen, M.; Li, W.-T.; Mao, X.-H.; Ji, S. Qualitative screening and quantitative determination of 569 pesticide residues in honeysuckle using ultrahigh-performance liquid chromatography coupled to quadrupole-Orbitrap high resolution mass spectrometry. J. Chromatogr. A 2019, 1606, 460374. [CrossRef]

23. Alaboudi, A.R.; Osaili, T.M.; Otoum, G. Quantification of mycotoxin residues in domestic and imported chicken muscle, liver and kidney in Jordan. Food Control. 2021, 132, 108511. [CrossRef]

24. Zhang, X.; Song, Y.; Jia, Q.; Zhang, L.; Zhang, W.; Mu, P.; Jia, Y.; Qian, Y.; Qiu, J. Simultaneous determination of 58 pesticides and relevant metabolites in eggs with a multi-functional filter by ultra-high performance liquid chromatography-tandem mass spectrometry. J. Chromatogr. A 2019, 1593, 81-90. [CrossRef] [PubMed]

25. Arce-López, B.; Lizarraga, E.; Flores-Flores, M.; Irigoyen, Á.; González-Peñas, E. Development and validation of a methodology based on Captiva EMR-lipid clean-up and LC-MS/MS analysis for the simultaneous determination of mycotoxins in human plasma. Talanta 2020, 206, 120193. [CrossRef] [PubMed] 